\title{
Development of domain-specific epistemological beliefs of physiotherapists: a longitudinal study
}

\author{
Martina Bientzle ${ }^{1}$, Ulrike Cress $^{1,2}$ and Joachim Kimmerle ${ }^{1,2^{*}}$ (D
}

\begin{abstract}
Background: Epistemological beliefs (EBs) and therapeutic health concepts are two important factors of influence that affect how healthcare professionals process treatment-relevant information. A previous investigation compared physiotherapy students' EBs and therapeutic health concepts with those of professionals in a cross-sectional study. That study design, however, did not allow for any conclusions about the temporal development of these concepts. This shortcoming has been addressed in the study presented here, which aimed to assess that temporal development.

Methods: In a longitudinal study, physiotherapists filled in a questionnaire that measured their personal EBs about physiotherapy and about medicine, as well as their biomedical and biopsychosocial therapeutic health concepts. The participants were first examined during their medical training (December 2011). The follow-up measure was about 3 years later when the participants had become professional physiotherapists (January 2015). The development of their EBs was examined using paired sample t-tests and Wilcoxon signed-rank test.

Results: The analysis was based on 41 participants who filled in the questionnaire at both time points and were working as physiotherapists at the time of the second measurement. There was a development of physiotherapyrelated and a development of medicine-related EBs: Physiotherapy-related as well as medicine-related EBs were more sophisticated when physiotherapists had already entered the working world than during their physiotherapy training. Due to psychometric problems of the scales, the development of their therapeutic health concepts could not be analyzed.

Conclusions: EBs are an important factor for (lifelong) learning. Physiotherapy-related and medicine-related EBs developed similarly in both domains. This is an indication that the temporal development of EBs is an expression of professionalization of healthcare personnel in their occupational field. The findings demonstrate that the development of EBs is not completed at the end of vocational training; it appears to be a development that continues even after the transition to professional life.
\end{abstract}

Keywords: Epistemological beliefs, Therapeutic health concepts, Longitudinal study, Development

\section{Background}

Health professionals must evaluate health-related information in the course of their daily work and take such information into consideration in their treatment decisions. Health-related information is often fragile and sometimes ambiguous [1-3]. Dealing with information in general and with health-related information in particular is influenced

\footnotetext{
* Correspondence: j.kimmerle@iwm-tuebingen.de

${ }^{1}$ Knowledge Construction Lab, Leibniz-Institut für Wissensmedien (IWM), Schleichstr. 6, 72076 Tuebingen, Germany

${ }^{2}$ Department of Psychology, University of Tuebingen, Schleichstr. 4, 72076 Tuebingen, Germany
}

(c) The Author(s). 2019 Open Access This article is distributed under the terms of the Creative Commons Attribution 4.0 International License (http://creativecommons.org/licenses/by/4.0/), which permits unrestricted use, distribution, and reproduction in any medium, provided you give appropriate credit to the original author(s) and the source, provide a link to the Creative Commons license, and indicate if changes were made. The Creative Commons Public Domain Dedication waiver (http://creativecommons.org/publicdomain/zero/1.0/) applies to the data made available in this article, unless otherwise stated. scientific information. Epistemological beliefs (EBs) are one important factor that has an impact on how health professionals process medical information [4-6]. EBs "are fundamental assumptions about the nature of knowledge, the certainty of knowing, the criteria and justifications for knowing" [p.29, 7]. As Roex and Degryse [6] pointed out, EBs are especially important for assessing one's own knowledge skills and learning strategies, and thus for making progress in acquiring medical knowledge. Acquiring knowledge is a lifelong process that consists of keeping up 
with the rapid advances in medical research. In the medical field [7], but also in other domains, such as mathematics [8] or reading comprehension [9], positive relationships between sophisticated EBs and learning success have frequently been observed (for an overview see [10]). EBs can be developed through problem-based learning settings and through arguing about different perspectives [11]. As a consequence of developing more sophisticated EBs, people tend to consider scientific knowledge to be more tentative, contextual, and subjective. Handling ill-structured problems [5] and dealing with patients with their individual medical histories and concerns are also relevant factors in the development of EBs [4] in medical contexts.

Previous research has shown that EBs can be regarded as domain-specific beliefs that also have a domaingeneral element $[12,13]$. Students evaluate knowledge in science as more certain, for example, than knowledge in psychology [14]. They also assess knowledge in biology to be more tentative than knowledge in physics [15]. At the same time, however, advanced students in general have more sophisticated EBs than freshmen. As "mental structures were likely to be both context- and contentdependent" (p.202, [16]) the investigation of the development of EBs should take a discipline-specific perspective into account.

Another important factor that has an impact on how health professionals process health-related information is their own personal therapeutic health concept [17]. In today's healthcare system, two therapeutic health concepts are relevant: a biomedical $(\mathrm{bm})$ therapeutic health concept and a biopsychological (bps) therapeutic health concept. This relevance is reflected in the common occurrence of the International Classification of Diseases (ICD) [18] (based on the $b m$ concept) and the International Classification of Functioning, Disability and Health (ICF) [19] (based on the bps concept). The widely used approach of patient-centeredness is closely linked to the bps concept [20, 21]. Health professionals' personal therapeutic health concepts influence how they communicate with patients [22] and how they handle treatment-relevant information [23, 24]. As physiotherapists aim to promote patients' participation and activity in their daily life, the bps concept is supposed to be more prevalent among physiotherapists than the $b m$ concept $[25,26]$. However, adopting this perspective is challenging for many physiotherapists [27], even though there is evidence that a bps approach can be more effective in treating patients than a $b m$ approach [28]. It is conceivable that the development of therapeutic health concepts could be part of the professionalization process of heath personnel. So far, however, not much is known about health professionals' temporal development of $\mathrm{bm}$ and bps concepts.
Epistemological beliefs and therapeutic health concepts are two important factors of influence that affect how health professionals process treatment-relevant information. A cross-sectional study found that EBs and therapeutic health concepts differed depending on the participants' training status [29]. Professional physiotherapists showed more sophisticated physiotherapy-related and more sophisticated medicine-related EBs than physiotherapy students. It was also found that professional physiotherapists had a more pronounced $b m$ concept than students. Moreover, professional physiotherapists had a more pronounced bps concept than first-year students. No conclusions can be drawn about the temporal development of the concepts from such a cross-sectional study. Thus, the present study aimed to examine the development of EBs and therapeutic health concepts over time with a longitudinal study design. Based on the previous considerations, the following hypotheses were stated:

Hypothesis 1: There will be a development of EBs:

a) Physiotherapy-related EBs will be more sophisticated when physiotherapists have already entered the working world than during their physiotherapy training.

b) Medicine-related EBs will be more sophisticated when physiotherapists have already entered the working world than during their physiotherapy training.

Hypothesis 2: There will be a development of the therapeutic health concept:

a) The $b m$ health concept will be more pronounced when physiotherapists have already entered the working world than during their physiotherapy training.

b) The bps health concept will be more pronounced when physiotherapists have already entered the working world than during their physiotherapy training.

\section{Methods}

\section{Participants}

Eighty-four participants took part in this longitudinal study at the first measurement point (December 2011; t1). At that time, they were all students at a school of physiotherapy in Tübingen, Germany (PT Academy). Twenty-nine students were first-year students and 55 were advanced students (second and third year). At t1, 80 students (95\%) were between 21 and 30 years old, only 4 students (5\%) were between 31 and 40. Fifty-eight were women, 26 were men. Forty-six physiotherapists (55\% of those who had participated in the first measurement) filled in the questionnaire at the second measurement point 
(January 2015; t2). At that time, they were working in different places (multiple answers were possible): Six were working in a hospital (four in an emergency hospital, two in a rehabilitation center), 37 were employed in a physiotherapy practice, two were self-employed in a physiotherapy practice, and three were working in the sports sector. Two of the participants were not working as physiotherapists at $\mathrm{t} 2$. The following analysis is based on those 41 participants who filled in the questionnaire at both measurement points and were working as physiotherapists at the time of $\mathrm{t} 2$ (see Fig. 1).

\section{Procedure}

The data collection at $\mathrm{t} 1$ took place at the PT Academy. After informing the students about privacy protection, their right to terminate their participation at any time without any disadvantage, and about the general purpose of the study, they gave written informed consent. Then they were asked to fill in the questionnaire (see below).

The follow-up measurement was conducted online 3 years later. All participants who were students at the PT Academy at $\mathrm{t} 1$ were contacted by e-mail from the secretary's office of the PT Academy. They were asked to fill in an online questionnaire. Participation took about $15 \mathrm{~min}$ and was compensated with the opportunity to take part in a lottery, where participants could win ten vouchers worth 15 Euros each. The datasets were linked by a code that the participants had created individually following a fixed procedure (the first letter of their mother's first name, the first letter of their father's first name, and their mother's year of birth).

\section{Measurements}

As described in the procedure of the cross-sectional analysis [29], the health-related EBs were measured with the Connotative Aspects of Epistemological Beliefs (CAEB) scale [30]. This scale was adapted to the domains of physiotherapy and medicine respectively. The participants assessed the knowledge in the field of physiotherapy and in medicine on seven-point semantic differential scales. Analogously to the cross-sectional study the CAEB-subscale texture was used, in which both domains were described with the same ten pairs of adjectives respectively. Sample items of this scale are "sorted - unsorted" or "absolute - relative", whereby "unsorted" and "relative" represented sophisticated EBs (see Table 1).

The $b m$ and bps health concepts were measured following the procedure presented previously [17, 29]. Participants rated the importance of five representative $b m$ terms, such as "diagnosis", and five characteristic bps concepts, such as "functionality", on six-point Likert scales ranging from 1 (not important) to 6 (very important) (see Table 2).

\section{Statistical analysis}

Data analysis was performed using IBM SPSS 20.0 for Windows [31]. Cronbach's Alpha was calculated to

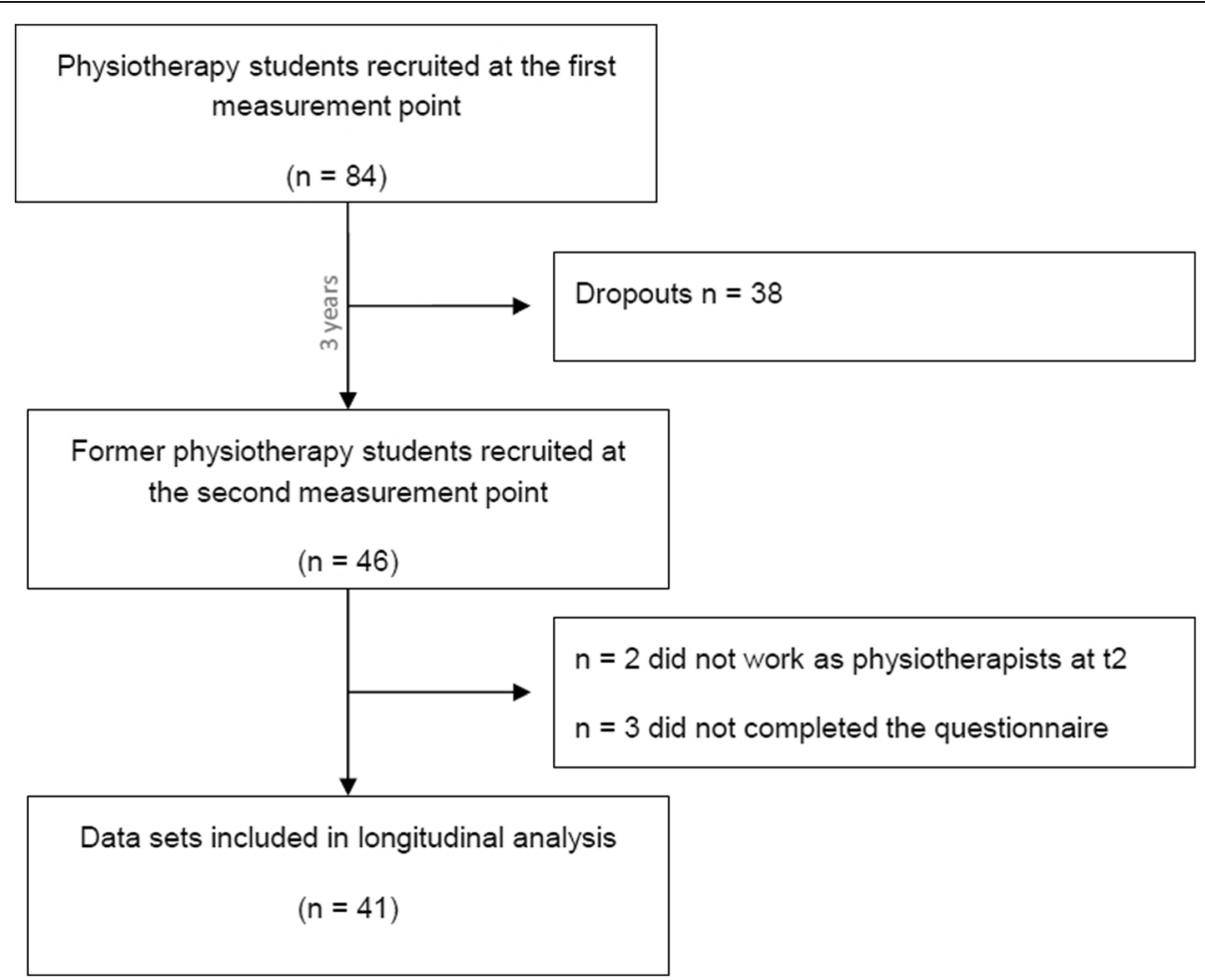

Fig. 1 Flow diagram of study design 
Table 1 The texture subscale of the Connotative Aspects of Epistemological Beliefs (CAEB) scale

\begin{tabular}{|c|c|c|c|}
\hline \multicolumn{4}{|c|}{ Knowledge in the domain of physiotherapy [or medicine respectively] is ... } \\
\hline 1 & objective & ロ-ロ-ロ-ロ-ロ-ロ-ロ & subjective \\
\hline 2 & confirmable & ロ-ロ-ロ-ロ-ロ-ロ-ロ & unconfirmable \\
\hline 3 & superficial & 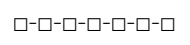 & profound \\
\hline 4 & exact & ロ-ロ-ロ-ロ-ロ-ロ-ロ & vague \\
\hline 5 & absolute & ๑-ロ-ロ-ロ-ロ-ロ-ロ & relative \\
\hline 6 & sorted & ロ-ロ-ロ-ロ-ロ-ロ-ロ & unsorted \\
\hline 7 & precise & ロ-ロ-ロ-ロ-ロ-ロ-口 & imprecise \\
\hline 8 & definite & ロ-ロ-ロ-ロ-ロ-ロ-口 & ambiguous \\
\hline $9^{r}$ & negotiated & ロ-ロ-ロ-ロ-ロ-ロ-ロ & discovered \\
\hline 10 & structured & ロ-ロ-ロ-ロ-ロ-ロ-ロ & unstructured \\
\hline
\end{tabular}

Seven-point semantic differential scales for measuring EBs about physiotherapy and medicine (texture subscale); reversely coded items are marked with a superscript ' $r$ '

determine internal consistency for all scales. All data are reported as means $(\mathrm{M}) \pm$ standard deviations and median values. For testing the hypotheses, paired sample t-tests were applied. Paired sample t-tests were also applied for comparing EBs regarding physiotherapy to EBs regarding medicine at $\mathrm{t} 1$ and $\mathrm{t} 2$. As it is discussed whether $\mathrm{t}$-tests should be used for Likert scales [32], Wilcoxon signedrank tests and Mann-Whitney U tests were also calculated, as nonparametric test equivalents to the t-tests.

The level of significance was set at $P<0.050$. Cohen's d scores were calculated as effect sizes of mean differences.

\section{Ethics statement}

This research was performed in accordance with the Declaration of Helsinki. The PT Academy's administration provided ethical approval for the participation of its students (due to legal specifications, the school administration was responsible for checking and approving the participation of its students). Regarding the follow-up

Table 2 Therapeutic health concepts scale

\begin{tabular}{ll}
\hline $\begin{array}{l}\text { How important are the following subjects for your therapeutic thinking } \\
\text { and acting? }\end{array}$ \\
\hline 1 & Functionality \\
$2^{*}$ & Diagnosis \\
$3^{*}$ & Science \\
$4^{*}$ & Evidence-based methods \\
5 & Limited activity of a patient \\
$6^{*}$ & Standardized tests \\
7 & Limited participation of a patient (in the social environment) \\
$8^{*}$ & Medical guidelines \\
9 & Mental health of a patient \\
10 & Requirements of the patient's everyday life
\end{tabular}

Six-point Likert scales for measuring the bm and bps concepts; bm items are marked with an asterisk $\left.{ }^{*}\right)$ measurement, this study had full approval of the ethics committee of the Leibniz-Institut für Wissensmedien (approval number: LEK 2013/035). All participants took part voluntarily and anonymously.

\section{Results}

\section{Health-related EBs}

The internal consistency of the CAEB-subscale texture was acceptable in both domains ( $\mathrm{t} 1: \alpha_{\text {phys }}=0.62 \alpha_{\text {med }}=$ $0.65 ; \mathrm{t} 2: \alpha_{\text {phys }}=0.66 ; \alpha_{\text {med }}=0.67$ ).

Hypothesis 1a predicted a development of physiotherapyrelated EBs. This assumption was supported by the data (see Table 3 for means and standard deviations). There were significant differences between the physiotherapyrelated EBs at $\mathrm{t} 1$ and $\mathrm{t} 2, \mathrm{t}(40)=-4.26, P<0.001, \mathrm{~d}=0.66$ (Wilcoxon signed-rank test: $\mathrm{z}=-3.50, P<0.001$ ).

Hypothesis $1 \mathrm{~b}$ predicted a development of medicinerelated EBs. This assumption was also supported by the data (see Table 3). Significant differences between the medicine-related EBs at $\mathrm{t} 1$ and $\mathrm{t} 2$ were found, $\mathrm{t}(40)=-5.04, P<0.001, \mathrm{~d}=0.79$ (Wilcoxon signedrank test: $\mathrm{z}=-4.15, P<0.001$ ).

In accordance with the cross-sectional study [29] an additional explorative analysis disclosed that first-year students showed greater development $\left(\mathrm{M}_{\text {Diff }}=0.82 \pm\right.$ $0.56)$ than the advanced students $\left(M_{\text {Diff }}=0.39 \pm 0.66\right)$ regarding medicine-related EBs, $\mathrm{t}(40)=1.97, P=0.028, \mathrm{~d}=$ 0.70 (Mann-Whitney-U-test: $U=105.00, P=0.024$ ).

Finally, like at $\mathrm{t} 1, \mathrm{t}(40)=3.67, P<0.001, \mathrm{~d}=0.57$ (Wilcoxon signed-rank test: $\mathrm{z}=-3.40, P=0.001$ ), the EBs regarding physiotherapy were still more sophisticated than EBs regarding medicine at $\mathrm{t} 2, \mathrm{t}(40)=2.50$, $P=0.009, \mathrm{~d}=0.39$ (Wilcoxon signed-rank test: $\mathrm{z}=-$ 2.27, $P=0.023$ ). The difference between physiotherapy- and medicine-related EBs were similar at both time points $\left(\right.$ Diff $_{\mathrm{t} 1}=0.28, \mathrm{SD}=0.49 ;$ Diff $_{\mathrm{t} 2}=0.21, \mathrm{SD}=$ $0.56 ; \mathrm{t}(40)=0.64, p=.262)$.

\section{Therapeutic health concepts}

The internal consistency of the subscale $b m$ health concept was poor ( $\mathrm{t} 1: \alpha=0.54 ; \mathrm{t} 2: \alpha=0.63$ ). The same was true of the bps heath concept scale ( $11: \alpha=0.57 ; \mathrm{t} 2: \alpha=0.52$ ). Due

Table 3 Health-related EBs

\begin{tabular}{lll}
\hline $\begin{array}{l}\text { EBs } \\
\text { Time of measurement }\end{array}$ & $\begin{array}{l}\text { EBs (texture) } \\
\text { regarding } \\
\text { knowledge in } \\
\text { physiotherapy }\end{array}$ & $\begin{array}{l}\text { EBs (texture) regarding } \\
\text { knowledge in medicine }\end{array}$ \\
\hline First measurement & $M=3.37 \pm 0.62$ & $M=3.09 \pm 0.57$ \\
Follow-up measurement & $M=3.82 \pm 0.59$ & $M=3.60 \pm 0.57$ \\
& Median $=3.80$ & Median $=3.50$ \\
\hline
\end{tabular}

Main effects of time of measurement on EBs regarding knowledge in physiotherapy and knowledge in medicine 
to this psychometric shortcoming, no analyses regarding therapeutic health concepts could be conducted.

\section{Discussion}

The aim of this longitudinal study was to contribute to a better understanding of the temporal development of health-related EBs and therapeutic health concepts of physiotherapy students over a period of 3 years. A previous cross-sectional study found that the EBs differed between students and professionals [29]. The longitudinal findings support these earlier results in that they demonstrate that both physiotherapy-related and medicinerelated EBs developed over time as people entered the working world. Former first-year students showed greater development of medicine-related EBs than former advanced students. However, this effect did not occur for physiotherapy-related EBs. In accordance with the crosssectional study [29], at both time points physiotherapists' physiotherapy-related EBs were more sophisticated than their medicine-related EBs. Interestingly, the difference between physiotherapy- and medicine-related EBs were quite similar at both time points. Similar developmental trajectories in EBs in different disciplines call into question the assumption that different domain-specific EBs tend to develop asynchronously [33]. Physiotherapy-related and medicine-related EBs emerged equally in both domains. Regarding the theoretical assumption that EBs are disciplinespecific but have a domain-general part, we cannot finally conclude whether the development we found relates in particular to a discipline-specific or to a general development of EBs. In future studies both discipline-specific and domain-general EBs should be assessed to address this issue. Based on the data presented here it is unclear whether this result would be transferable to other health domains or to other healthcare professionals. This is an aspect that should also be addressed in future research.

Concerning therapeutic health concepts, the scale of the $b m$ and $b p s$ measure had to be excluded due to psychometric flaws. It is likely that the internal consistency was low because the scale consists of only 5 items and the number of items has an impact on Cronbach's alpha coefficient [34]. The research question as to whether there is temporal development of the $b m$ and $b p s$ concepts cannot be answered with this study. The generalizability of the results might be reduced by the fact that all of the participating students were recruited from the same school of physiotherapy, whose educational approach was mainly influenced by a bps perspective. Generalizability is also limited because the sample consisted exclusively of physiotherapists trained in Germany; physiotherapy training in Germany differs from training in other countries in that most German physiotherapists attend vocational schools instead of universities. As often is the case in longitudinal studies that take several years to complete, there was a substantial dropout rate that could potentially have biased the study results (in terms of a selection bias). As the same pattern of results was found as in the cross-sectional study, however, it is quite unlikely that the findings in this study result merely from a selection bias.

\section{Practical implications}

As has been shown in several knowledge domains, EBs are an important factor that has an impact on how people process information. It is a key factor for (lifelong) learning, and the temporal development of EBs seems to be an expression of the professionalization of an individual in her or his working field. The findings demonstrate that the development of EBs is not completed at the end of vocational training: it is rather a development that continues even after the transition to professional life. The finding that both physiotherapyrelated and medicine-related EBs developed comparably in both domains could be a hint that the temporal development of EBs is discipline-specific and can be interpreted as an indicator of professionalization.

In order to foster the development of EBs during the education process, it might be an option to confront students with close-to-reality learning settings, using for example problem-based learning methods [35], which can facilitate the professionalization process [36]. Another approach could be to develop interprofessional learning settings [37], such as interprofessional videos [38] or interprofessional online learning platforms $[39,40]$.

\section{Conclusions}

EBs are highly relevant for learning, education, and information processing. Physiotherapy-related and medicinerelated EBs developed similarly in both domains. The development of EBs appears to be a continuing development throughout one's working life. Putting students into realistic learning scenarios already during their physiotherapy training, could be a promising strategy to foster the development of EBs.

\section{Abbreviations \\ Bm: Biomedical; Bps: Biopsychological; CAEB: Connotative Aspects of Epistemological Beliefs scale; EBs: Epistemological beliefs; ICD: International Classification of Diseases; ICF: International Classification of Functioning, Disability and Health}

\section{Acknowledgements}

The authors would like to thank the PT Academy Tuebingen for their organizational support and the participants for investing their personal time in participating.

\section{Authors' contributions}

$M B, U C$, and JK contributed to the conception and design of this study. MB made substantial contributions to the acquisition of data and performed the statistical analysis. MB and JK were responsible for drafting the article. UC contributed to its critical revision. All authors approved the final manuscript for publication. All authors have agreed both to be personally accountable 
for the author's own contributions and to ensure that questions related to the accuracy or integrity of any part of the work, even ones in which the author was not personally involved, are appropriately investigated, resolved, and the resolution documented in the literature.

\section{Funding}

The research reported here was supported in part by a grant from the ScienceCampus Tuebingen Informational Environments (TP5.2-18065015) awarded to JK. The authors also acknowledge support by Deutsche Forschungsgemeinschaft and Open Access Publishing Fund of Tuebingen University. None of these funding bodies has exerted any influence on the design of the study and collection, analysis, interpretation of data and on writing the manuscript.

\section{Availability of data and materials}

Data are available on request to Martina Bientzle.

\section{Ethics approval and consent to participate}

This research was performed in accordance with the Declaration of Helsinki. The PT Academy's administration provided ethical approval regarding participation of its students (due to legal specifications, the school administration was responsible for checking and approving the participation of its students). Regarding the follow-up measurement this study had full approval by the ethics committee of the Leibniz-Institut für Wissensmedien (approval number: LEK 2013/035). All participants took part voluntarily and anonymously. They gave written informed consent and were informed about privacy protection, their right to terminate participation at any time without any disadvantage, and about the general purpose of the study.

\section{Consent for publication}

Not applicable.

\section{Competing interests}

The authors declare that they have no competing interests.

Received: 16 May 2019 Accepted: 18 October 2019

Published online: 01 November 2019

\section{References}

1. Sniderman $A D$, Furberg $C D$. Why guideline-making requires reform. J Am Med Assoc. 2009;301:429-31. https://doi.org/10.1001/jama.2009.15.

2. Kimmerle J, Flemming D, Feinkohl I, Cress U. How laypeople understand the tentativeness of medical research news in the media: an experimental study on the perception of information about deep brain stimulation. Sci Commun. 2015;37:173-89. https://doi.org/10.1177/1075547014556541.

3. Kienhues D, Stadtler M, Bromme R. Dealing with conflicting or consistent medical information on the web: when expert information breeds laypersons' doubts about experts. Learn Instruct. 2011;21:193-204. https://doi.org/10.1016/j.learninstruc.2010.02.004.

4. Knight LV, Mattick K. 'When I first came here, I thought medicine was black and white': making sense of medical students' ways of knowing. Soc Sci Med. 2006;63:1084-96. https://doi.org/10.1016/j.socscimed.2006.01.017.

5. Roex A, Clarebout G, Dory V, Degryse J. Can ill-structured problems reveal beliefs about medical knowledge and knowing? A focus-group approach. BMC Med Educ. 2009;9:62. https://doi.org/10.1186/1472-6920-9-62.

6. Roex A, Degryse J. Introducing the concept of epistemological beliefs into medical education: the hot-air-balloon metaphor. Acad Med. 2007;82:61620. https://doi.org/10.1097/ACM.0b013e3180556abd.

7. Oh SA, Chung EK, Han ER, Woo YJ, Kevin D. The relationship between medical students' epistemological beliefs and achievement on a clinical performance examination. Korean J Med Educ. 2016;28:29-34. https://doi.org/10.3946/kjme.2016.7.

8. Muis KR. Personal epistemology and mathematics: a critical review and synthesis of research. Rev Educ Res. 2004;74:317-77. https://doi.org/10.3102/ 00346543074003317

9. Schommer M. Epistemological development and academic performance among secondary students. J Educ Psychol. 1993;85:406-11. https://doi.org/ 10.1037/0022-0663.85.3.406.

10. Greene JA, Cartiff BM, Duke RF. A meta-analytic review of the relationship between epistemic cognition and academic achievement. J Educ Psychol. 2018;110:1084-111. https://doi.org/10.1037/edu0000263.
11. Roex DV, A. Let's talk about thinking. Med Educ. 2012;46:1147-9. https://doi. org/10.1111/medu.12038.

12. Buehl MM, Alexander PA, Murphy PK. Beliefs about schooled knowledge: domain specific or domain general? Contemp Educ Psychol. 2002;27:41549. https://doi.org/10.1006/ceps.2001.1103.

13. Muis KR, Bendixen LD, Haerle FC. Domain-generality and domain-specificity in personal epistemology research: philosophical and empirical reflections in the development of a theoretical framework. Educ Psychol Rev. 2006;18: 3-54. https://doi.org/10.1007/s10648-006-9003-6.

14. Hofer BK. Dimensionality and disciplinary differences in personal epistemology. Contemp Educ Psychol. 2000;25:378-405. https://doi.org/10. 1006/ceps.1999.1026.

15. Tsai C-C. Biological knowledge is more tentative than physics knowledge: Taiwan high school adolescents' views about the nature of biology and physics. Adolescence. 2006;41:691-703.

16. Richardson JTE. Epistemological development in higher education. Educ Res Rev. 2013;9:191-206. https://doi.org/10.1016/j.edurev.2012.10.001.

17. Bientzle M, Cress U, Kimmerle J. How students deal with inconsistencies in health knowledge. Med Educ. 2013;47:683-90. https://doi.org/10.1111/ medu.12198.

18. World Health Organization. International statistical classification of disease and related health problems, tenth revision (ICD-10). Geneva: World Health Organization; 1992.

19. World Health Organization. The International Classification of Functioning, Disability and Health (ICF). Geneva: World Health Organization; 2001.

20. Langberg EM, Dyhr L, Davidsen AS. Development of the concept of patientcentredness-A systematic review. Pat Educ Couns. 2019. https://doi.org/10. 1016/j.pec.2019.02.023

21. Larivaara P, Kiuttu J, Taanila A. The patient-centred interview: the key to biopsychosocial diagnosis and treatment. Scand J Prim Health Care. 2001;19: 8-13. https://doi.org/10.1080/02813430119395.

22. Bientzle M, Griewatz J, Kimmerle J, Küppers J, Cress U, Lammerding-Koeppel M. Impact of scientific versus emotional wording of patient questions on doctor-patient communication in an internet forum: a randomized controlled experiment with medical students. J Med Internet Res. 2015;17: e268. https://doi.org/10.2196/jmir.4597.

23. Domenech J, Sánchez-Zuriaga D, Segura-Ortí E, Espejo-Tort B, Lisón JF. Impact of biomedical and biopsychosocial training sessions on the attitudes, beliefs, and recommendations of health care providers about low back pain: a randomised clinical trial. Pain. 2011;152:2557-63. https://doi. org/10.1016/j.pain.2011.07.023.

24. O'Sullivan K, O'Sullivan P, O'Sullivan L, Dankaerts W. Back pain beliefs among physiotherapists are more positive after biopsychosocially orientated workshops. Physiother Pract Res. 2013;34:37-4. https://doi.org/10.3233/PPR2012-0012.

25. Stenmar L, Nordholm LA. Swedish physical therapists' beliefs on what makes therapy work. Phys Ther. 1994;74:1034-9. https://doi.org/10.1093/ptj/ 74.11.1034.

26. Jorgensen P. Concepts of body and health in physiotherapy: the meaning of the social/cultural aspects of life. Physiother Theor Pract. 2000;16:105-15. https://doi.org/10.1080/095939800407295.

27. França AA, dos Santos V, Lordelo Filho R, Pires KF, Lagoa KF, Martins WR. 'It's very complicated': perspectives and beliefs of newly graduated physiotherapists about the biopsychosocial model for treating people experiencing non-specific low back pain in Brazil. Musculoskelet Sci Pract. 2019;42:84-9. https://doi.org/10.1016/j.msksp.2019.04.011.

28. Kamper SJ, Apeldoorn AT, Chiarotto A, Smeets RJEM, Ostelo RWJG, Guzman J, et al. Multidisciplinary biopsychosocial rehabilitation for chronic low back pain: cochrane systematic review and meta-analysis. BMJ. 2015;350:h444. https://doi.org/10.1136/bmj.h444

29. Bientzle M, Cress U, Kimmerle J. Epistemological beliefs and therapeutic health concepts of physiotherapy students and professionals. BMC Med Educ. 2014;14:208. https://doi.org/10.1186/1472-6920-14-208.

30. Stahl E, Bromme R. The CAEB: an instrument for measuring connotative aspects of epistemological beliefs. Learn Instr. 2007;17:773-85. https://doi. org/10.1016/j.learninstruc.2007.09.016.

31. IBM Corporation. IBM SPSS statistics for Windows, version 20.0. New York: IBM Corporation; 2011.

32. Norman G. Likert scales, levels of measurement and the "laws" of statistics. Adv Health Sci Educ. 2010;15:625-32. https://doi.org/10.1007/ s10459-010-9222-y. 
33. Schommer-Aikins M. Explaining the epistemological belief system: introducing the embedded systemic model and coordinated research approach. Educ Psychol. 2004;39:19-29. https://doi.org/10.1207/ s15326985ep3901_3.

34. Tavakol M, Dennick R. Making sense of Cronbach's alpha. Int J Med Educ. 2011;2:53-5. https://doi.org/10.5116/ijme.4dfb.8dfd.

35. Barrows HS. A taxonomy of problem-based learning methods. Med Educ. 1986;20:481-6. https://doi.org/10.1111/j.1365-2923.1986.tb01386.x.

36. Jones NL, Peiffer AM, Lambros A, Guthold M, Johnson AD, Tytell M, Ronca AE, Eldridge JC. Developing a problem-based learning (PBL) curriculum for professionalism and scientific integrity training for biomedical graduate students. J Med Ethics. 2010;36:614-9. https://doi.org/10.1136/jme.2009.035220.

37. Guraya SY, Barr $\mathrm{H}$. The effectiveness of interprofessional education in healthcare: a systematic review and meta-analysis. Kaohsiung J Med Sci. 2018:34:160-5. https://doi.org/10.1016/j.kims.2017.

38. Grosser J, Bientzle M, Shiozawa T, Hirt B, Kimmerle J. Acquiring clinical knowledge from an online video platform: a randomized controlled experiment on the relevance of integrating anatomical information and clinical practice. Anat Sci Educ. 2019;12:478-84. https://doi.org/10.1002/ase.1841.

39. Cain J, Chretien K. Exploring social media's potential in interprofessional education. J Res Interprof Pract Educ. 2013:1-7. https://doi.org/10.22230/ jripe.2013v3n2a110.

40. Vasset F, Brynhildsen S, Kvilhaugsvik B. Interprofessional learning through a digital platform. J Res Interprof Pract Educ. 2019;9:1-12. https://doi.org/10. 22230/jripe.2019v9n1a282.

\section{Publisher's Note}

Springer Nature remains neutral with regard to jurisdictional claims in published maps and institutional affiliations.

Ready to submit your research? Choose BMC and benefit from:

- fast, convenient online submission

- thorough peer review by experienced researchers in your field

- rapid publication on acceptance

- support for research data, including large and complex data types

- gold Open Access which fosters wider collaboration and increased citations

- maximum visibility for your research: over $100 \mathrm{M}$ website views per year

At $\mathrm{BMC}$, research is always in progress.

Learn more biomedcentral.com/submissions 